\title{
TRANSPARENCIA Y ACCESO A LA INFORMACIÓN EN ESPAÑA
}

\section{TRANSPARENCY AND ACCESS TO INFORMATION IN SPAIN}

\author{
JOSÉ ANTONIO MONTILLA MARTOS ${ }^{1}$
}

\begin{abstract}
RESUMO: A transparência e o direito de acesso à informação pública são instrumentos fundamentais para o controle cidadão do exercício do poder. O índice de democracia de um Estado pode ser medido pela consolidação do reconhecimento e regulação do direito de acesso à informação pública. Um dos elementos mais inovadores é, juntamente ao direito de acesso à informação, a regulação da denominada transparência ativa, isto é, a obrigação da Administração de publicar informação ativamente. Com essa perspectiva, farei uma referência inicial à transparência ativa para então discutir o direito de acesso à informação pública, especialmente seus limites enquanto elemento fundamental na configuração do Direito. Três problemas podem ser apontados na lei espanhola, inicialmente: o direito à informação não está configurado como direito fundamental, mas sim como direito legal; muita informação ficou de fora do âmbito de aplicação da lei; a estreita vinculação do Conselho de Transparência à Administração é criticável. PALAVRAS-CHAVE: Direito de Acesso à Informação; Transparência; Publicidade.
\end{abstract}

\begin{abstract}
Transparency and the right to access public information are fundamental tools for citizen control of the exercise of power. A State's democracy index can be measured by the consolidation of the recognition and regulation of the right to access public information. One of the novel elements is that, in addition to the right to access information, statutes regulate the so-called active transparency, that is, the Administration's obligation to actively publish information. From this perspective, I will make an initial reference to active transparency and then develop the right to access public information, specially its limits as a fundamental element of the configuration of Law. Three problems in the Spanish statute can be found so far: the right to information is not characterized as a constitutional right, but rather as a legal right; much information has remained outside of the statute's scope of application; the close ties of the Transparency Council with the Administration can be subject to criticism.

KEYWORDS: Right to Access Information; Transparency; Publicity.
\end{abstract}

SUMÁRIO: Introdução; 1. A Publicidade Ativa; 2. O Direito ao Acesso à Informação Pública; 3. O Futuro da Transparência; Referências.

Artigo recebido em 29.06.2015. Artigo aceito para publicação em 30.06.2015 mediante convite.

${ }^{1}$ Professor Catedrático de Direito Constitucional da Faculdade de Direito da Universidade de Granada.montilla@ugr.es 
SUMMARY: Introduction; 1. Active Publicity; 2. The Right to Acess Public Information; 3. The Future of Transparency; References.

SUMARIO: Introducción; 1. La Publicidad Activa; 2. El Derecho de Acceso a la Información Pública; 3. El Futuro de la Transparencia; Referencias.

\section{INTRODUCCIÓN}

La transparencia y el derecho de acceso a la información pública son instrumentos fundamentales para el control ciudadano del ejercicio del poder. El índice de democracia de un Estado se puede medir por la consolidación del reconocimiento y la regulación del derecho de acceso a la información pública. En algunas partes del mundo las leyes de transparencia tienen gran tradición. Así, en Suecia la primera Ley de esta naturaleza data de 1766. En cualquier caso, en los últimos decenios se han extendido a todos los Estados democráticos. En la Unión Europea, tras aprobarse la ley española, sólo Malta, Chipre y Luxemburgo no tienen ley de transparencia.

En España este debate se ha desarrollado con mucho retraso. La Constitución de 1978 establece en su artículo 105 b) que la ley regulará "el acceso de los ciudadanos a los archivos y registros administrativos, salvo en lo que afecte a la seguridad y defensa del Estado, la averiguación de los delitos y la intimidad de las personas". Por tanto, se recoge el derecho de acceso a la información como un derecho de configuración legal que se ubica, además, fuera del título de los derechos, en el Título IV dedicado a "Gobierno y Administración".

Como sabemos, hasta 2013 no se ha aprobado la Ley 19/2013, de 9 de diciembre, de transparencia, acceso a la información pública y buen gobierno (en adelante LTBG), tras un largo proceso de tramitación parlamentaria. Como en otros países el impulso político se ha producido en un contexto de crisis de legitimación democrática, sospechas de corrupción y debilidad gubernamental. Intenta ser una respuesta a la crisis institucional manifestada en España a partir de las movilizaciones del 15-M.

Por ello, estamos empezando a aplicar la Ley. Además, los títulos de la Ley referidos a la transparencia han tenido un periodo de vacatio legis muy amplio, de un año, por lo que su vigencia se ha iniciado en diciembre de 2014. Incluso para los órganos de las Comunidades Autónomas y las entidades locales no entrará en vigor hasta diciembre de 2015. Es el momento, por tanto, de compartir experiencias con otros Estados que también están empezando a desarrollar políticas de transparencia, como es el caso de Brasil pues su Ley es de 2011. No obstante, analizar una Ley que en la práctica aún no se ha podido aplicar nos hace limitar el contenido de estas páginas a la presentación de los rasgos fundamentales de la ley española.

Uno de los elementos más novedosos es que, junto al derecho de acceso a la información, se regula la denominada publicidad activa, esto es, la obligación que tiene la administración de publicar información. A medida que 
vaya desarrollándose esta publicidad activa acaso será innecesario el ejercicio de este derecho a solicitar información y acceder a ella por la ciudadanía. Si toda la información está a disposición no será preciso solicitarla a través del ejercicio del derecho. No obstante, es un tránsito que apenas está empezando a producirse. En la ley que describimos coexisten, por tanto, la obligación de publicar datos con el derecho de la ciudadanía a solicitar información, con la regulación detallada del procedimiento y sus garantías.

Desde esta perspectiva, haré una referencia inicial a la publicidad activa para detenerme en el derecho de acceso a la información pública, especialmente en sus límites en cuanto elemento fundamental en la configuración del Derecho.

La Ley 19/2013, de transparencia y buen gobierno, es legislación básica, dictada al amparo de los dispuesto en los artículos 149.1.1 CE (condiciones de igualdad en el ejercicio de los derechos), 149.1.13 CE (ordenación general de la actividad económica) y 149.1.18 CE (bases del régimen jurídico de las administraciones públicas). Distintas Comunidades Autónomas están aprobando sus propias leyes de transparencia, a partir de esas bases estatales, concretando la aplicación del principio en su ámbito territorial. Así ha ocurrido en Andalucía (Ley 1/2014), Canarias (Ley 12/2014), Cataluña (Ley 19/2014), La Rioja (Ley 3/2014) o Murcia (Ley 12/2014). Incluso otras lo habían hecho con anterioridad a la existencia de la ley del Estado. En la mayoría de los casos estamos ante la discutible técnica de repetir el contenido de la ley estatal en el ordenamiento autonómico que se vincula a la no participación de las Comunidades Autónomas en la elaboración de legislación estatal a través de una auténtica cámara de representación territorial. Debemos entender, en cualquier caso, que las obligaciones establecidas en la ley básica constituyen un mínimo que podrá ser ampliado por las CCAA. Por ello, en estas leyes regionales se introducen otros contenidos adicionales, más allá de obligar específicamente a su propia Administración. Así en el caso de Canarias encontramos una regulación de infracciones y sanciones de la que carece la legislación del Estado.

\section{LA PUBLICIDAD ACTIVA}

La publicidad activa está regulada en los artículos 5 a 11 de la LTBG y constituye uno de los aspectos más positivos de la regulación española, aunque debemos esperar a su concreción. Es la obligación que tienen los sujetos sometidos al alcance de esta Ley de publicar "de forma periódica y actualizada, la información cuyo conocimiento sea relevante para garantizar la transparencia de su actividad relacionada con el funcionamiento y control de la actuación pública". Supone un salto cualitativo respecto a la publicidad pasiva derivada del derecho de acceso a la información. Las autoridades deben poner la información a disposición de la ciudadanía, sin esperar al planteamiento de la solicitud.

La Ley establece un criterio general de publicación periódica y actualizada de la información más relevante. Detalla la obligación de publicar toda la 
información sobre proyectos normativos, planes y su evaluación, presupuestos y su ejecución, contratos, convenios, subvenciones, retribuciones de altos cargos, etc. Hay que divulgar a través de internet toda aquella información que permita a los ciudadanos participar, controlar y contribuir, con ello, a una mejor gestión pública. Se trata de centralizar toda esa información y ponerla en formatos que permitan su fácil localización. La centralización de la información se hace en el denominado Portal de la Transparencia.

Los sujetos obligados son todos aquellos a los que se les puede solicitar información al estar incluidos en el artículo 2.1 LTBG. La información a publicar es la relevante para garantizar la transparencia de su actividad relacionada con el funcionamiento y control de la actuación pública.

Los artículos 6 a 8 de la Ley establecen el mínimo de información relevante que debe ser publicada. En primer lugar, se refiere a la información institucional, organizativa y de planificación que incluye los datos relativos a la estructura, régimen jurídico y responsable de cada ente administrativo (artículo 6.1 LTBG), así como los planes y programas anuales y plurianuales (artículo 6.2 LTBG). En segundo lugar, la información de relevancia jurídica que incluye: las directrices, instrucciones, acuerdos, circulares o respuestas a consultas planteadas en cuanto contengan una interpretación jurídica; los anteproyectos de Ley y los proyectos de Decretos legislativos; los proyectos de Reglamentos; las memorias e informes que conformen los expedientes de elaboración de los textos normativos y los documentos que, conforme a la legislación sectorial vigente, deban ser sometidos a un periodo de información pública durante su tramitación (artículo 7 LTBG). Como se advierte, no se mencionan los documentos vinculados a la tramitación de las leyes en cuanto las Cortes Generales sólo están vinculadas por esta Ley en lo que se refiere a su actividad administrativa, no en relación a las funciones que le atribuye la Constitución: ejercicio de la potestad legislativa, aprobación de los Presupuestos y control de la acción del Gobierno (artículo 66.2 CE). En tercer lugar, se incluye en la obligación de publicidad activa la información económica, presupuestaria y estadística que remite a los contratos, convenios, encomiendas de gestión, subvenciones y ayudas públicas de cada administración, los presupuestos y estados de ejecución de las cuentas anuales, la información de altos cargos y personal de designación política (retribuciones, indemnizaciones de altos cargos, compatibilidad, declaración anual de bienes y actividades), la información estadística de calidad de servicios públicos o la relación de bienes inmuebles de administraciones (artículo 8 LTBG).

Toda esta información debe recogerse en el Portal de la Transparencia, instrumento centralizado de la Administración General del Estado para la publicidad activa dependiente del Ministerio de Presidencia que debe adecuarse a los principios de accesibilidad, interoperabilidad y reutilización. Pero, además, no sólo debe contener la información más relevante de publicación obligada sino también aquella información "que se solicite con más frecuencia" (art. 10.2 LTBG), lo que resultará más difícil de cotejar. 
Sin embargo, la presentación del Portal, tras un año de espera, ha producido cierta decepción tanto por las limitaciones de acceso como por la ausencia de determinada información que se considera relevante. Así, en primer lugar, sólo se incluye información correspondiente al año 2014, de forma que para acceder a información de años anteriores debe ser solicitada expresamente a través del ejercicio del derecho de acceso a la información pública. En segundo lugar, sólo se refiere, por expresa previsión legal, a la información de los órganos administrativos o a la referente a la actividad administrativa de otros órganos constitucionales y, en tercer lugar, se excluyen los documentos de tramitación (notas, informes, etc) que pueden ser valiosos para comprender bien la decisión final adoptada por el órgano administrativo.

El cumplimiento de las obligaciones establecidas en la Ley por la Administración General del Estado será objeto de control por el Consejo de Transparencia y Buen Gobierno, al que nos referimos luego. Este podrá dictar resoluciones en las que se establezcan medidas para el cese del incumplimiento y el inicio de actuaciones disciplinarias, incluso el incumplimiento reiterado tendrá la consideración de infracción grave a los efectos de aplicación a sus responsables del régimen disciplinario previsto en la correspondiente normativa reguladora. Como se advierte, dicho régimen disciplinario no se incluye en esta Ley.

\section{EL DERECHO DE ACCESO A LA INFORMACIÓN PÚBLICA}

Una vez analizada la publicidad activa, nos detenemos en el derecho de acceso a la información pública. Según el artículo 12 LTBG: "Todas las personas tienen derecho a acceder a la información pública, en los términos previstos en el artículo 105 b) de la Constitución española, desarrollados por esta Ley". A partir de este reconocimiento se analizan a continuación la naturaleza del derecho; su sujeto, objeto y ámbito subjetivo de aplicación; los límites a su ejercicio; el procedimiento para hacerlo efectivo y las garantías reconocidas en la Ley.

\subsection{Naturaleza del Derecho}

La naturaleza del derecho de acceso a la información pública constituye un aspecto fundamental pues de ello dependerán las garantías jurisdiccionales, e incluso normativas, que le resultan aplicables. Se trata de determinar si estamos ante un derecho constitucional de configuración legal, reconocido en el artículo 105 b) CE, o ante un derecho fundamental al conectarse con el artículo 20 CE como un contenido del derecho a recibir información. El debate no es teórico. Los derechos fundamentales tienen en España una especial protección respecto a los derechos que no tienen esa consideración, tanto en lo que se refiere a las garantías normativas (reserva de ley orgánica) como a las jurisdiccionales (procedimiento preferente y sumario ante los tribunales ordinarios y amparo constitucional ante el Tribunal Constitucional). Y el valor de un derecho depende, como se sabe, de sus garantías. 
La Ley se presenta como el desarrollo del derecho reconocido en el artículo 105 b) de la Constitución. Por tanto, se sitúa fuera de la sección primera del capítulo segundo del Título I de la Constitución (artículos 15 a 29 CE) donde se contienen los derechos fundamentales y las libertades públicas con las garantías apuntadas antes. Sin embargo, eso no impide de forma absoluta su consideración como derecho fundamental, si se produce la conexión con alguno de los expresamente reconocidos. Así ocurre con el derecho a la asistencia jurídica gratuita, incardinado en el artículo 119 CE pero vinculado al derecho fundamental a la tutela judicial efectiva del artículo 24 CE. El Tribunal Constitucional ha considerado que es un derecho instrumental respecto del derecho de acceso a la jurisdicción pues su finalidad inmediata radica en permitir el acceso a la justicia para interponer pretensiones u oponerse a ellas, a quienes no tienen medios económicos suficientes (STC 180/2003). Incluso también ha establecido la conexión con el derecho fundamental a la asistencia letrada (artículo 24.2 CE) pues incluye el derecho a que sea asignado un letrado de oficio cuando su situación le haga acreedor de ello según lo determinado por las leyes en aplicación del artículo 119 CE (STC 114/1998) ${ }^{2}$.

Ciertamente, en relación al derecho que nos ocupa, el Tribunal Constitucional no ha establecido esa conexión. Incluso, en la STC 161/1988 rechazo una solicitud de amparo que pretendía sustentarse, entre otros fundamentos, en el artículo 105 b) aduciendo que los derechos reconocidos en ese precepto no eran susceptibles de amparo. En consecuencia, siquiera implícitamente está descartando su conexión con un derecho fundamental, en concreto con el artículo 20 CE (libertades de expresión e información). Por tanto, desde la perspectiva del legislador, con ese sustento jurisprudencial, no resulta posible esa conexión y, en consecuencia, no estamos ante una manifestación de la libertad de información sino ante un derecho constitucional autónomo de configuración legal. Es, por tanto, un derecho constitucional no fundamental desarrollado por ley ordinaria y con las garantías que le reconoce esa ley. No es un derecho instrumental al servicio de otros derechos sino un derecho autónomo al servicio del control de la actuación pública conectado con el Estado democrático.

Sin embargo, esta interpretación puede ser cuestionada si atendemos a la doctrina del Tribunal Europeo de Derechos Humanos. Este Tribunal ha venido admitiendo desde la sentencia Társaság contra Hungría, de 14 de abril de 2009, que el derecho de acceso a los documentos públicos es "un elemento esencial del ejercicio (...) del derecho a la libertad de expresión". De una forma nítida, la sentencia Youth Initiative for Human Rights contra Serbia de 25 de junio de 2013 establece expresamente que "la noción de libertad para recibir

\footnotetext{
${ }^{2}$ Cfr. J. GARBERÍ LLOBREGAT, "Artículo 119”, en M.E. Casas Baamonde, M. Rodríguez-Piñero y Bravo-Ferrer, Comentarios a la Constitución Española. XXX Aniversario, WoltersKluwer, Madrid, 2008.
} 
información abarca un derecho de acceso a la información" (apartado 20) ${ }^{3}$. Por tanto, como los derechos fundamentales deben interpretarse de conformidad a los tratados y acuerdos internacionales ratificados por España, conforme a la apertura internacional de los derechos del artículo $10.2 \mathrm{CE}$, resulta claro que en virtud de esta doctrina del Tribunal Europeo de Derechos Humanos el derecho fundamental a recibir libremente información veraz debe incorporar el derecho de acceso a la información.

Es cierto que a esta conclusión puede oponerse la doctrina establecida por el Tribunal Constitucional en relación a la reagrupación familiar. Conforme a reiterada doctrina del Tribunal Europeo de Derechos Humanos la reagrupación familiar forma parte del derecho a la vida familiar, reconocido en el Convenio Europeo de Derechos Humanos. Sin embargo, el Tribunal Constitucional ha sostenido, en una singular interpretación de lo que significa "interpretación" que la doctrina del Tribunal Europeo de Derechos Humanos permite interpretar los derechos fundamentales ya reconocidos en la Constitución pero no configurar nuevos derechos y en nuestra Constitución no se reconoce el derecho a la vida familiar sino el derecho a la intimidad familiar, con un contenido distinto, que no incluye, por tanto, el derecho a la reagrupación familiar. Este se incardina en nuestra Constitución, según esta doctrina, en el principio rector de protección de la familia del artículo 39 CE; fuera, por tanto, de los derechos fundamentales y sin las garantías que a éstos ofrece nuestro ordenamiento constitucional ${ }^{4}$. Es claro que de mantener esta posición, puede considerar que el derecho de acceso a la información pública no se reconoce en nuestra Constitución en el artículo 20 sino en el artículo 105 b) y, por tanto, no le resulta aplicable la doctrina del Tribunal Europeo de Derechos Humanos. Sin embargo, si en el caso del derecho a la reagrupación familiar ya era difícilmente sostenible la posición del Tribunal Constitucional español, aún lo es más en este supuesto dada la nítida posición del Tribunal Europeo de Derechos Humanos.

\footnotetext{
${ }^{3}$ Sobre esta doctrina del Tribunal Europeo de Derechos Humanos, G. RollnertLiern, "El Derecho de Acceso a la Información Pública como Derecho Fundamental: una valoración del debate doctrinal a propósito de la Ley de Transparencia", Teoría y Realidad Constitucional, 34, 2014, páginas 364-367.

${ }^{4}$ La STC 236/2007 ha reconocido implícitamente esta interpretación y la ha aplicado de manera expresa al supuesto concreto de la reagrupación familiar. El objeto del conflicto ha sido la duda de constitucionalidad planteada en torno a diversos artículos de la Ley en los que se hacía una remisión en blanco al reglamento para que regule las condiciones de ejercicio del derecho y otras cuestiones como el tiempo previo de convivencia que deberá acreditar el cónyuge reagrupado separado para acceder a un permiso de residencia independiente. Si estamos ante un derecho incluido en el ámbito de protección de un derecho fundamental cual es la intimidad familiar esta remisión en blanco que hace la Ley al reglamento vulnera la reserva de ley, esto es, una de las garantías normativas de los derechos fundamentales constitucionalmente reconocida (art. 53.1 CE). Sin embargo, en la STC 236/2007 se declara la conformidad constitucional de estos preceptos al considerar que no regulan ni desarrollan el derecho a la intimidad familiar, por lo que "ni estaban sometidos a la reserva de ley orgánica, ni a la reserva de ley establecida para los derechos y libertades reconocidos en el capitulo II, por lo cual las remisiones reglamentarias no habrían infringido aquellas disposiciones constitucionales" (FJ 11).
} 


\subsection{Titularidad, Objeto y Ámbito Subjetivo de Aplicación del Derecho}

La titularidad del derecho viene reconocida en la LTBG de la forma más amplia posible: "Todas las personas" (artículo 12). Esto significa que es titular del derecho cualquier persona física o jurídica, sin limitación alguna en razón de nacionalidad o residencia.

En cuanto al objeto estamos ante el derecho a acceder a la información pública. Por ello, en principio, debe presumirse que el objeto del derecho es la información pública, esto es, el contenido y no los soportes documentales en los que se contiene. El artículo 105 b) CE había establecido un contenido mínimo del derecho. Al establecer el derecho de acceso a los "archivos y registros administrativos" resulta claro que la Ley reguladora debía incluir ese contenido. No obstante, el artículo 13 LTBG va más allá de esa exigencia constitucional al concretar que se entiende por información pública. Conforme al artículo 13 LTBG información pública son "los contenidos o documentos, cualquiera que sea su formato o soporte, que obren en poder de alguno de los sujetos incluidos en el ámbito de aplicación de este título y que hayan sido elaborados o adquiridos en el ejercicio de sus funciones". Esto significa, por un lado, que incluye no sólo a los contenidos sino también a los soportes, esto es, el acceso a los documentos propiamente dichos; por otro lado, que no sólo alcanza a "archivos y registros administrativos" sino a toda la información que tengan en su poder los sujetos enumerados en los artículos 2, 3 y 4 de esta Ley, aún con las limitaciones y restricciones que en ella se establecen, a las que nos referimos a continuación.

En consecuencia, un elemento básico de esta Ley es el ámbito subjetivo de aplicación: los sujetos obligados a poner a disposición de la ciudadanía los documentos (publicidad activa) y a atender las solicitud de información producidas en ejercicio del derecho de acceso (publicidad pasiva).

Para establecer el ámbito subjetivo de aplicación se aplica un doble criterio: a) aquellos sujetos que ejerzan una función pública; b) los sujetos que aún no ejerciendo una función pública reciban financiación pública. En cualquier caso, respecto a este segundo grupo, los sujetos privados que reciben financiación pública, se establece una limitación importante. Conforme al artículo 5.1 LTBG no están obligados a publicar de forma periódica y actualizada la información cuyo conocimiento sea relevante para garantizar la transparencia sino únicamente a atender las demandas de información efectuadas en ejercicio del derecho de acceso a la información pública. Esto conlleva, por tanto, un distinto nivel de sujeción que dificulta la aplicación de la Ley.

Los primeros afectados son, por tanto, todos aquellos sujetos que desarrollan una función pública. Ello incluye entidades de diverso tipo:

a) las administraciones públicas territoriales, que en España son el Estado, las Comunidades Autónomas, las provincias y los municipios;

b) los organismos y entidades públicas considerados como administraciones públicas en esta Ley. Es el caso de los organismos autónomos, las agencias 
estatales, las entidades públicas empresariales y las entidades de Derecho Público que tengan atribuidas funciones de regulación o supervisión sobre un determinado sector o actividad. También las entidades de Derecho Público con personalidad jurídica propia vinculadas a una administración pública o dependiente de ellas, incluidas las Universidades públicas. Y, por supuesto, las entidades gestores de la Seguridad Social y mutuas de accidentes de trabajo y enfermedades profesionales colaboradoras de la Seguridad Social.

c) Organismos y entidades que están sometidas a la Ley sólo en relación con sus actividades sujetas al Derecho Administrativo. Es el caso de las corporaciones de Derecho Público pero especialmente de diversos órganos constitucionales que durante la tramitación de la ley se han incorporado a su ámbito de aplicación. El art. $2.1 \mathrm{~g}$ ) menciona a la Casa del Rey, el Congreso de los Diputados, el Senado, el Tribunal Constitucional, el Consejo General del Poder Judicial, el Banco de España, el Consejo de Estado, el Defensor del Pueblo, el Tribunal de Cuentas, el Consejo Económico y Social, así como las instituciones autonómicas análogas. No resulta fácil determinar en estos supuestos la aplicación de la Ley pues ¿cuáles son las actividades "sujetas al Derecho administrativo"? Parece alcanzar a las actividades vinculadas al personal, la gestión patrimonial y la contratación pero no al ejercicio de sus funciones en el marco constitucional. Así, en relación a la Casa del Rey, que fue incorporada al ámbito de aplicación durante la tramitación parlamentaria se aplica sólo a las actividades que se rigen por el Derecho administrativo pero ¿cuáles son estos supuestos? ${ }^{5}$. En todo lo demás, la transparencia y el derecho de acceso a la información en relación a estos órganos se rige por sus normas reguladores. En este sentido, puede producirse la ilusión óptica de que la Ley alcanza también a estos órganos e instituciones cuando en realidad su incidencia es sumamente limitada y la transparencia debe lograrse mediante la modificación de otras leyes. Hubiera sido más adecuado que en paralelo a la aprobación de esta Ley se hubieran modificado también otras disposiciones contenidas en las fuentes reguladoras de estos órganos para garantizar efectivamente la transparencia y el derecho de acceso a la información en relación a estos órganos.

d) Sujetos públicos que no son administraciones públicas pero quedan también sometidas a lo establecido en esta Ley. Son las sociedades mercantiles en cuyo capital social la participación directa o indirecta de las entidades públicas sea superior al cincuenta por ciento; las fundaciones del sector público, esto es, las que se constituyan por las entidades del sector público por la naturaleza pública del fundado y de las aportaciones al patrimonio

\footnotetext{
${ }^{5}$ Además, conforme a la Disposición Adicional sexta, "la Secretaría General de la Presidencia del Gobierno será el órgano competente para tramitar el procedimiento mediante el que se solicite el acceso a la información que obre en poder de la Casa de su Majestad el Rey, así como para conocer de cualquier otra cuestión que pudiera surgir derivada de la aplicación por este órgano de las disposiciones de esta Ley".
} 
fundacional y las asociaciones constituidas por las administraciones, organismos y entidades previstos en este artículo.

e) Finalmente, también se aplica la Ley a las entidades privadas financiadas con fondos públicos. El artículo 3 LTBG menciona dos tipos de entidades. En primer lugar, los partidos políticos, los sindicatos y las organizaciones empresariales; por otro, aquellas entidades privadas que reciban recursos públicos superiores a 100.000 euros al año o cuando suponga el $40 \%$ de sus ingresos anuales, siempre que sean más de 5.000 euros. En cualquier caso, en relación a estas entidades se establecen dos condiciones: las obligaciones previstas en la Ley lo son en relación a los fondos públicos que perciban y al uso que hagan de esos fondos; además, en segundo lugar, la obligación es de publicidad pasiva, no activa, esto es, existe respecto a ellas el derecho de acceso a la información pero no tienen la obligación de publicar dicha información. Las restantes entidades privadas quedan al margen de la aplicación de esta Ley.

Se advierten, por tanto, distintos niveles de sujeción a la Ley. El nivel máximo afecta a las administraciones territoriales y a cualesquiera administraciones públicas. Están obligadas no sólo a atender las solicitudes de información planteadas por cualquier persona (publicidad pasiva) sino también a publicar la información cuyo conocimiento sea relevante para garantizar la transparencia de su actividad. Además, la obligación alcanza a todos sus ámbitos de actuación. Junto a estas, otros órganos o entidades tienen un nivel de sujeción distinto. Así, los órganos constitucionales incluidos en el ámbito de aplicación de la Ley esta vinculados en relación a sus actividades sujetas a Derecho administrativo pero no a su actividad ordinaria. Por señalar el ejemplo más señero, el Congreso de los Diputados y el Senado no quedan vinculados por esta Ley en el ejercicio de la actividad legislativa, presupuestaria y de control, para ello resultaría necesario que los reglamentos parlamentarios lo establecieran de forma expresa, como ya ha ocurrido en alguna Comunidad Autónoma (Andalucía). Finalmente, las entidades privadas incluidas en el ámbito subjetivo de aplicación lo están en relación al ejercicio del derecho de acceso a la información, no a la obligación de publicar información, y sólo en relación a los fondos públicos que han percibido.

\subsection{Excepciones y Límites al Ejercicio del Derecho de Acceso a la Información Pública}

Las excepciones y límites de este derecho constituyen su elemento fundamental. Su alcance efectivo no depende tanto de su configuración primera sino de las posibilidades que abre el legislador para denegar la información apelando a intereses públicos o privados que merecen ser protegidos.

Es evidente que en cualquier sistema jurídico se prevén límites a este derecho de acceso a la información para la salvaguarda de otros bienes públicos o privados. Estos límites deben tener tres rasgos: a) deben ser establecidos por ley; b) deben ser tasados mediante una lista exhaustiva y sin 
utilizar conceptos jurídicos indeterminados; $c$ ) deben vincularse a la tutela de bienes públicos o privados concurrentes. A su vez, pueden distinguirse las limitaciones absolutas, que en ningún caso permiten acceder a la información, y las limitaciones relativas, sometidas a ponderación.

El artículo 14 LTBG enumera una serie de límites para la protección de bienes públicos. Son, en todos los casos, límites relativos, sometidos al criterio de ponderación, y se expresan de manera genérica. En este sentido, pueden constituir límites al ejercicio del derecho de acceso a la información pública: a) la seguridad nacional; b) la defensa; c) las relaciones exteriores; d) la seguridad pública; e) la prevención, investigación y sanción de ilícitos penales, administrativos o disciplinarios; f) la igualdad de las partes en los procesos judiciales y la tutela judicial efectiva; g) las funciones administrativas de vigilancia, inspección y control; h) los intereses económicos y comerciales; i) la política económica y monetaria; j) el secreto profesional y la propiedad intelectual e industrial; $k$ ) la confidencialidad o el secreto requerido en procesos de toma de decisión; l) la protección del medio ambiente.

Como se ha dicho, en relación a estas materias expresadas de forma genérica procede el juicio de ponderación en los supuestos concretos en los que se puedan aducir para rechazar el acceso a la información pública. Se trata de valorar si la limitación del derecho de acceso está justificada y es proporcionada a su objeto y finalidad de protección, atendiendo a las circunstancias del caso concreto, especialmente a la concurrencia de un interés público o privado superior que justifique el acceso. Por tanto, el juicio de ponderación deberá tener en cuenta la importancia de conocer la información no sólo desde una perspectiva pública (opinión pública) sino también atendiendo al interés privado frente al posible perjuicio que se pueda originar. A su vez, las resoluciones administrativas que incorporan la ponderación para limitar el derecho de acceso a la información deben ser objeto de publicidad activa, previa disociación de los datos de carácter personal que contuvieran.

Pero, más allá del juicio de proporcionalidad, en este supuesto adquiere una especial importancia lo que se ha denominado el test del perjuicio, esto es, la posibilidad de restringir el derecho cuando la divulgación de la información suponga un perjuicio para algo o para alguien ${ }^{6}$. A la hora de establecer esta ponderación entre el acceso a la información y el perjuicio causable deben tenerse en cuenta diversos elementos. En primer lugar, debemos partir de que perjuicio no significa afectación. Cualquier información afecta a los bienes públicos o privados a los que se refiere pero ello no significa necesariamente que produzca un perjuicio. En segundo lugar, el juicio ponderativo debe hacerse caso por caso, no por materias. Esto significa que por referirse la información a defensa, seguridad del Estado u otras de las materias que pueden actuar como límites del derecho de acceso a la información, incluso

\footnotetext{
${ }^{6}$ Cfr. E. Guichot (coord.), Transparencia, Acceso a la Información Pública y Buen Gobierno. Estudios sobre la Ley 19/2013, de 9 de diciembre, Madrid, Tecnos, 2014, páginas 427-448 (E-book).
} 
constitucionalmente previstas, no significa que se cause un perjuicio sino que habrá de estarse al supuesto concreto. En tercer lugar, el perjuicio deberá argumentarse, no basta con una invocación genérica a la posibilidad de que se produzca. Finalmente, en cuarto lugar, las limitaciones al acceso a la información deben tener el mínimo alcance necesario. En este sentido puede tener importancia el principio de "acceso parcial" recogido en el art. 16 LTBG. Según esta disposición cuando "la aplicación de alguno de los límites previstos en el artículo 14 no afecte a la totalidad de la información, se concederá el acceso parcial previa omisión de la información afectada por el límite, salvo que de ello resulte una información distorsionada o que carezca de sentido. En este caso, deberá indicarse al solicitante que parte de la información ha sido omitida".

Pero más allá de estos límites vinculados a la salvaguarda de bienes públicos, el principal límite al derecho de acceso a la información pública es su posible conflicto con el derecho fundamental a la protección de datos de carácter personal. En algunos casos, como veremos a continuación, es un límite absoluto, respecto al cual no cabe ponderación.

En este sentido, en el ordenamiento constitucional español el derecho a la protección de datos de carácter personal del artículo 18.4 CE es un derecho autónomo, distinto del derecho a la intimidad pero instrumental a éste. Es el derecho a decidir sobre el uso de sus datos personales entendido como la información sobre una persona física identificada o identificable. En concreto, es el derecho a controlar el flujo de información referido a una persona (STC 11/1998) y su contenido esencial está configurado por los derechos del afectado a consentir sobre la recogida y uso de sus datos personales, así como el derecho a ser informado de quien posee nuestros datos personales y poder oponerse a su disposición y uso (STC 292/2000). En consecuencia, puede comprenderse que estamos ante el límite de aplicación más habitual frente al derecho de acceso a la información pública. Por ello, la Ley de Transparencia ha sido más precisa en relación al conflicto con este derecho que respecto a otros como el derecho a la intimidad, que también puede verse afectado y tiene el reconocimiento constitucional expreso del artículo 105 b) CE.

En concreto, el art. 15 LTBG establece cuatro supuestos distintos, en los que este límite juega de distintas formas:

En primer lugar, cuando la información se refiere a datos referidos a la ideología de la persona, incluida la afiliación sindical, religión o creencias, el acceso a la información sólo se podrá autorizar cuando se cuente con el consentimiento expreso y por escrito del afectado, salvo que dicho afectado hubiese hecho manifiestamente públicos los datos con anterioridad a que se solicitase el acceso.

En segundo lugar, cuando son datos referidos al origen racional, la salud, la vida sexual o la comisión de infracciones penales o administrativas que no conllevasen la amonestación pública del infractor, se requiere el consentimiento 
expreso del afectado (que ya no debe ser necesariamente por escrito) o también se podrá acceder a ellos cuando lo disponga una norma con rango de ley.

En tercer lugar, cuando la información solicitada no contuviera datos especialmente protegidos, de los apuntados en los dos párrafos anteriores, para conceder el acceso el órgano al que se dirija deberá ponderar de forma suficientemente razonada, por un lado, el interés público en la divulgación de la información y, por otro, los derechos de los afectados cuyos datos aparezcan en la información solicitada, en particular su derecho a la protección de datos de carácter personal. Incluso la Ley enuncia una serie de criterios que deberán tomarse en consideración para realizar la ponderación.

En cuarto lugar, cuando la información se refiera a datos meramente identificativos relacionados con la organización, funcionamiento o actividad pública del órgano se concederá el acceso a la información con carácter general, salvo que por las características concretas del caso pueda prevalecer la protección de datos personales u otros derechos constitucionalmente protegidos sobre el interés público de la divulgación.

En cualquier caso, para evitar el conflicto y poder ejercer el derecho de acceso a la información resulta relevante lo establecido en el apartado cuarto del artículo 15 LTBG según el cual "no será aplicable lo establecido en los artículos anteriores si el acceso se efectúa previa disociación de los datos de carácter personal de modo que se impida la identificación de las personas afectadas". En muchos casos basta la disociación para acceder a la información sin vulnerar el derecho a la protección de datos pero habrá que estar a cada uno de los supuestos.

En conclusión, el derecho a la protección de datos de carácter personal supone un límite importante al ejercicio de este derecho de acceso a la información pública. En la práctica, la virtualidad del acceso a la información, y por tanto de la transparencia, va a depender de cómo se resuelva este conflicto en los casos concretos. En principio, parece establecerse la prevalencia de la reserva cuando están en juego datos íntimos y de la publicidad cuando se trata de datos relacionados con la organización, el funcionamiento o el gasto público.

\subsection{Procedimiento para Hacer Efectivo el Derecho}

La Ley de Transparencia pretende establecer un procedimiento simple, ágil y asequible para todos los ciudadanos, con plazos breves de resolución, para el ejercicio del derecho de acceso a la información pública. Se establece, además, la participación de los terceros afectados para ponderar mejor, pero sin otorgarles un derecho de veto. Todo ello con costes económicos no disuasorios. La regla general es la gratuidad del acceso a dependencias públicas con el pago exclusivamente de los costes de reproducción de los documentos, en su caso.

Cualquier persona puede presentar la solicitud de información ante el titular del órgano administrativo o entidad que la posea (artículo 19.1 LTBG) 
en cualquiera de las lenguas oficiales en el territorio en que radique el órgano administrativo al que solicita la información. Si se considera no competente debe remitirla a quien lo sea. En el contenido de la solicitud deben incluirse los datos del solicitante (no puede ser anónima), la información que se solicita, una dirección de contacto, preferentemente electrónica, a efectos de comunicaciones y el medio a través del cual se prefiere acceder a la información. No existe obligación de motivar la solicitud aunque puede exponer los motivos por los que se solicita la información y podrán ser tenidos en cuenta cuando se dicte la resolución. La ausencia de motivación no puede ser por sí sola causa de rechazo de la solicitud.

En cualquier caso, se permite la inadmisión mediante resolución motivada y se enumeran las causas de inadmisión: información en curso de elaboración o de publicación general; información de carácter auxiliar o de apoyo (notas, borradores, opiniones, resúmenes, comunicaciones e informes internos); información para cuya divulgación sea necesaria una acción previa de reelaboración; dirigidas a un órgano en cuyo poder no obre la información cuando se desconozca el competente o que la solicitud sea manifiestamente repetitiva o tenga un carácter abusivo no justificado (arículo 18 LTBG).

En cuanto a la tramitación del procedimiento se prevé la audiencia a terceros cuando pudiera afectar a sus derechos e intereses (artículo 19.3 LTBG) y un plazo de 15 días para que se hagan alegaciones. La resolución en la que se conceda o deniegue el acceso deberá notificarse al solicitante y a los terceros afectados que así lo hayan solicitado en el plazo máximo de un mes desde la recepción de la solicitud de información, ampliable a otro mes si se aduce el volumen o la complejidad de la información solicitada, previa notificación al solicitante.

Esta resolución deberá estar motivada cuando deniegue el acceso, conceda el acceso parcial o a través de una modalidad distinta a la solicitada y cuando haya concedido el acceso pese a la oposición de tercero.

Transcurrido el plazo máximo para resolver sin que se haya dictado y notificado resolución expresa se entenderá que la solicitud ha sido desestimada (artículo 15.4 LTBG). Se ha criticado que el silencio sea negativo. Deben tenerse en cuenta, en cualquier caso, varias cuestiones que seguramente lo justifican: en primer lugar, es la solución habitual en las leyes de otros países; en segundo lugar, la posible afectación de derechos de terceros, como hemos comprobado, encaja mal con el silencio positivo; en tercer lugar, la ficción jurídica del silencio permite actuar al solicitante recurriendo y exigiendo, en su caso, responsabilidad política y disciplinaria y, finalmente, no podemos olvidar que el artículo 20.6 LTBG señala que el incumplimiento reiterado de la obligación de resolver en plazo tiene la consideración de infracción grave.

Finalmente, el artículo 22 LTBG regula la formalización del acceso a la información. Se realiza preferentemente por vía electrónica en el plazo de 10 días desde la resolución reconociendo el derecho. Si hay oposición de 
terceros debe esperarse a que transcurra el plazo para interponer recurso contencioso administrativo sin que se haya interpuesto o se haya resuelto confirmando el derecho de recibir información.

\subsection{Garantías del Derecho}

Las resoluciones dictadas sobre la solicitud de acceso a la información pública son recurribles directamente ante la jurisdicción contenciosoadministrativa, sin perjuicio de la interposición de una reclamación potestativa ante el Consejo de la Transparencia y Buen Gobierno (artículo 20.5 LTBG). Por tanto, es importante distinguir los dos ámbitos de garantía: la garantía jurisdiccional y la potestativa garantía que ofrece el Consejo de la transparencia.

En relación a la garantía jurisdiccional lo más importante es destacar que al no configurarse en la Ley el derecho de acceso a la información pública como un derecho fundamental no resulta aplicable el procedimiento preferente y sumario regulado en los artículos 114 y siguientes de la Ley 29/1998, de 13 de julio, reguladora de la jurisdicción contencioso-administrativa. Tampoco, evidentemente, resulta posible el recurso de amparo constitucional del artículo 43 de la Ley Orgánica 2/1979, del Tribunal Constitucional.

De cualquier forma, lo singular en este caso es la reclamación potestativa ante el Consejo de la Transparencia prevista en el artículo 24 LTBG, con un carácter potestativo y previo a su impugnación en vía contencioso-administrativa.

El Consejo de la Transparencia pretende ser una institución autónoma e independiente, con personalidad jurídica propia, que permita una respuesta rápida y eficaz a las reclamaciones de los ciudadanos. Sus fines concretos son promover la transparencia de la actividad pública, velar por el cumplimiento de las obligaciones de publicidad y salvaguardar el ejercicio del derecho de acceso a la información pública, más allá de garantizar la observancia de las disposiciones de buen gobierno.

La creación de este Consejo podía tener sentido por distintos motivos. En primer lugar porque, como se ha dicho, no sólo resuelve los conflictos sobre el ejercicio del derecho de acceso a la información sino que también hace pedagogía de la transparencia, absolutamente necesaria en un país sin una cultura de la transparencia. En segundo lugar, porque su intermediación puede limitar la litigiosidad en torno al acceso a la información y hacer posible, en definitiva, dicho acceso sin esperar a que muchos años después se pronuncien los tribunales. En tercer lugar, porque se distingue del organismo de protección de datos y, por tanto, compensa la actuación de un órgano que siempre va a adoptar una actitud más propensa a ese derecho y, por tanto, limitadora del acceso a la información pública.

El problema deriva de la composición del Consejo, como se ha advertido al configurarlo a finales de 2014, pues su vinculación gubernamental tanto en la designación de sus miembros como en su posible separación limita en la práctica la independencia que la Ley le reconoce formalmente. El Consejo está compuesto por el Presidente y la Comisión de Transparencia. De cualquier 
forma, el órgano gira en torno a la figura de su Presidente, que es nombrado por el Consejo de Ministros a propuesta del Ministro de Hacienda y puede ser separado también por el Gobierno por una serie de causas entre las que se incluye un hipotético incumplimiento grave de sus funciones, considerado por el propio Gobierno. La designación deberá ser refrendada por la mayoría absoluta del Congreso. A su vez, la Comisión está compuesta por un diputado, un senador y otros vocales designados por la Secretaria de Estado de Administraciones Públicas, el Tribunal de Cuentas, el Defensor del Pueblo, la Agencia Española de Protección de Datos y la Autoridad Independiente de Responsabilidad Fiscal. Hubiera sido importante establecer un procedimiento de designación del Presidente y de la Comisión menos vinculado al Gobierno y a la organización administrativa pues, en definitiva, es el órgano que vela por el cumplimiento de la transparencia por parte de las administraciones públicas. La designación debería haber sido parlamentaria, con una mayoría más cualificada que obligue a designar una persona de consenso y los designados no deberían proceder del aparato administrativo por cuya transparencia vela ni, por supuesto, de la política activa.

\section{EL FUTURO DE LA TRANSPARENCIA}

Estamos ante una Ley aprobada en España con mucho retraso y pese a ello no se ha abierto a la nueva época en el acceso a la información pública vinculada a la existencia de una ciudadanía más activa que reclama su participación efectiva en la vida pública. Tiene elementos positivos. Destacamos en este sentido el reconocimiento de la publicidad activa como una obligación en la actividad administrativa o también que la Ley pretende ser precisa, no puramente nominal o principialista, como suele ocurrir con algunas leyes de este tipo. La mayor parte de su contenido, específicamente lo que aquí nos interesa, entró en vigor en diciembre de 2014 por lo que resulta imposible hacer un balance de su aplicación. Ya se ha creado el órgano que velará por el cumplimiento de los contenidos de la Ley, el Consejo de la Transparencia y el Buen Gobierno, y se ha puesto en marcha la página web a través de la cual se desarrollará la publicidad activa: el Portal de la Transparencia.

Sin embargo, en este momento inicial podemos plantear algunos problemas que plantea nuestra Ley, y que no le hace ser, ni mucho menos, de las más avanzadas del mundo. En primer lugar, el derecho a la información no se configura como un derecho fundamental, sino como un derecho de configuración legal, con las limitaciones en las garantías normativas y jurisdiccionales que ello conlleva. En segundo lugar, mucha información ha quedado fuera del ámbito de aplicación de la ley. Se ha vinculado sólo a la actividad administrativa y, por tanto, queda fuera la actividad no estrictamente administrativa de los distintos órganos constitucionales desde el Congreso y el Senado a la Casa del Rey, además de toda la documentación preparatoria de las decisiones finalmente adoptadas. En tercer lugar, resulta criticable la estrecha vinculación del Consejo de la Transparencia a la Administración 
General del Estado e incluso la vinculación política directa o indirecta de algunos de sus integrantes.

Aún rechazando sus insuficiencias, con estos instrumentos debemos trabajar en España. El reto es lograr un más adecuado control de la actividad pública a través de la ciudadanía pues más participación ciudadana en asuntos públicos significa mejor democracia.

\section{REFERENCIAS}

E. GUICHOT (coord.), Transparencia, Acceso a la Información Pública y Buen Gobierno. Estudios sobre la Ley 19/2013, de 9 de diciembre, Madrid, Tecnos, 2014, páginas 427-448 (E-book).

G. ROLLNERTLIERN, "El Derecho de Acceso a la Información Pública como Derecho Fundamental: una valoración del debate doctrinal a propósito de la Ley de Transparencia", Teoría y Realidad Constitucional, 34, 2014, páginas 364-367.

J. GARBERÍ LLOBREGAT, "Artículo 119", en M.E. Casas Baamonde, M. RodríguezPiñero y Bravo-Ferrer, Comentarios a la Constitución Española. XXX Aniversario, WoltersKluwer, Madrid, 2008. 